\title{
Forecasting Post-War Tourist Arrivals to Sri Lanka Using Dynamic Transfer Function Modeling Method
}

\author{
Gnanapragasam $\mathrm{SR}^{1}$ and Cooray TMJA ${ }^{2}$ \\ ${ }^{1}$ Department of Mathematics and Computer Science, The Open University of Sri Lanka \\ ${ }^{2}$ Department of Mathematics, University of Moratuwa, Sri Lanka
}

\begin{abstract}
Tourism plays a big role in terms of economics in the development of a country. The arrivals were less during the war period in Sri Lanka due to the uncertainty of security. Forecasting tourist arrivals is essential for planning, policy making and budgeting purposes. The objective of the study is to fit a model to predict tourist arrivals by using dynamic transfer function (DTF) modeling method. The monthly tourist arrivals from June 2009 to June 2016 are extracted from the annual reports of Sri Lanka tourism development authority for this study. Prior to model fittings, the following techniques were carried out: Augmented Dickey- Fuller test, Kruskal-Wallis test, difference method, auto-correlation function and partial auto-correlation function. For model fitting, dynamic transfer function model for univariate time series process was employed. AndersonDarling test, Lagrange's Multiplier test and White's General test were applied for the residuals analysis. To evaluate the performance of the model on the basis of the fit of the forecasting, mean absolute percentage error (MAPE) was taken into account. It is stated that, over 7.3 million tourists had visited the island during the study period. Further it is noted that, every year there is a positive growth rate. It reveals that, there is dramatic increase in total tourist arrivals after the war. Soon after the war in Sri Lanka, a rapid increase in growth rate in the year 2010 is also observed. According to the MAPE value, it is concluded that, the fitted DTF model explains over $90 \%$ accuracy in terms of forecasting tourist arrivals. Based on the ex-post forecast, it is expected that nearly 1.105 million tourists will come to Sri Lanka in the last six months in 2016. It is approximately 14\% increase in the arrivals over the last six months in the year 2015.
\end{abstract}

KEYWORDS: Dynamic transfer function, forecasting, tourist arrivals. 


\section{INTRODUCTION}

Tourism, as an industry, contributes to the national economy of a country in a large scale. Now it is one of the largest and fastest growing economic sectors in the world. The case studies (Balaguer \& Cantavella, 2002; Durbarry, 2004) discovered the impact of tourism on economic growth in Spanish and Mauritius respectively. An empirical study (King \& Gamage, 1994) addressed the impact of tourism on economic growth in Sri Lanka. There is a significant causal relationship from tourism receipts to the gross domestic product (GDP) of Sri Lanka (Wickramasinghe \& Ihalanayake, 2006). There were several set-backs in the tourism development process in Sri Lanka such as global economic crisis in 2009, Tsunami in 2004 and the internal conflict from the year 1983 to the year 2009. During the conflict period, mainly due to the uncertainty of security, tourists did not come to Sri Lanka. Nevertheless, the conflict is over by now.

The records in Sri Lanka tourism development authority (SLTDA) show that, the tourist arrivals are dramatically increasing after the internal conflict. As per the statistical annual report 2015 of SLTDA, due to the rise of the arrivals to Sri Lanka, tourism was able to upgrade its rank to the third level as the largest source of foreign exchange earner of the national economy in 2015. Those that ranked above tourism were Foreign Remittances and Textiles \& Garments industries. The portion of contribution of tourism to total foreign exchange earnings in 2015 amounted to $12.4 \%$. It reveals that contribution of tourism to the GDP is significantly high.

Tourism basically contains two types as domestic and international. This study is mainly focused only on the international tourist arrivals to Sri Lanka. Prediction of tourist arrivals is essential for planning, policy making and budgeting purposes. Thus, the objective of the study is to fit a model to predict international tourist arrivals by using dynamic transfer function (DTF) modelling method.

\section{BACKGROUND}

The general theme of the studies (Bermudez et al., 2007; Witt et al., 1992; Lim \& McAleer, 2001; Akuno et al., 2015) says that forecasting accuracy is high in exponential smoothing modelling and this approach obtains a level of accuracy comparable to those of other more sophisticated models. However, the empirical studies (Cho, 2001; Chu, 1998; Loganathan \& Yahaya, 2010; Chang et al., 2011; Dimitrios et al., 2012; Saayman et al., 2010; Prasert et al., 2008) show that autoregressive integrated moving average (ARIMA) modelling is overall the most accurate method for forecasting international tourist arrivals. Nevertheless, the state space model outperforms alternative approaches for short-term forecasting and also produces sensible long-term forecasts (Athanasopoulos \& Hyndman, 2006). On the other hand, the neural network modelling method performs the best in these studies (Law, 2000; Burger et al., 2001; Cho, 2003). Therefore, it is not that easy to assign a modelling method to a specific region or a country to forecast tourism demand. Hence, all possible modelling methods have to be employed and based on the accuracy of the forecast, best method can be recommended.

Furthermore, a comprehensive review of published studies on tourism demand modelling and forecasting since 2000 was carried out (Song $\& \mathrm{Li}, 2008)$. One of the key findings of this review is that the methods used in analysing and forecasting the demand for tourism had been more varied. As far as the forecasting accuracy is concerned, this review shows that, there is no single model that consistently outperforms other models in all situations. Therefore, it is better to consider several approaches, to tourism demand in Sri Lanka, to identify the best model based on the forecasting accuracy.

According to the literature, empirical studies of time series behaviour of the post war international tourist arrivals to Sri Lanka had 
been carried out using different modelling approaches.

They are as follows: the classical time series decomposition approach (Kurukulasooriya \& Lelwala, 2014) with $96 \%$ forecasting accuracy, Box-Jenkin's modelling and Holt - Winter's Exponential Smoothing approaches (Gnanapragasam \& Cooray, 2016(a) \& 2016(b)) with nearly $95 \%$ and $88 \%$ forecasting accuracy respectively and State Space modelling approach (Gnanapragasam et al., 2016) with 94\% forecasting accuracy. However, dynamic transfer function (DTF) model was not tried so far for the purpose of predicting international tourist arrivals to Sri Lanka. Therefore, this study attempts to fit tourist arrivals to Sri Lanka using DTF modelling approach.

\section{MATERIALS \& METHODS}

The monthly international tourist arrivals, from June 2009 to June 2016, recorded in the annual statistical reports of Sri Lanka tourism development authority are extracted for this study.

\subsection{Preliminary Analysis}

At the preliminary stage prior to fit the dynamic transfer function model (DTF) model, the following techniques were carried out to get an idea about the data and its behaviour.

\subsubsection{Plot of Time Series}

It is to inspect for extreme observations, missing data, or elements of non-stationary such as trend or seasonality or cyclic pattern or irregular variations.

\subsubsection{Augmented Dickey- Fuller test}

Augmented Dickey- Fuller (ADF) test is used to test whether the series has a unit root. It is to confirm, statistically, that the stationary of series in terms of trend availability.
The test statistic for the model $Y_{t}=\rho Y_{t-1}+u_{t}$ with $-1<\rho<1$, is $D F=\frac{\hat{\rho}}{S E(\hat{\rho})} \sim t_{n-1}$ where $Y_{t}$ is the response variable at time $t, u_{t}$ is the white noise and $n$ is the number of observations. The hypothesis to be tested in this test is $\mathrm{H}_{0}$ : series is non-stationary $(|\rho|=1)$ versus $\mathrm{H}_{1}$ : series is stationary $(|\rho|<1)$.

\subsubsection{Kruskal- Wallis test}

Kruskal- Wallis test is used to confirm the seasonality in the series. The hypothesis to be tested in this test is, $\mathrm{H}_{0}$ : series has no seasonality versus $\mathrm{H}_{1}$ : series has seasonality. The test statistic of ruskal- Wallis test is defined as:

$$
H=\frac{12}{N(N+1)} \sum_{i=1}^{n_{i}} \frac{R_{i}^{2}}{n_{i}}-3(N+1) \square \chi_{L-1}^{2}
$$

where $N$ is the total number of rankings, $R_{i}$ is the sum of the rankings in a specific season, $n_{i}$ is the number of the rankings in a specific season and $L$ is the length of the season.

\subsubsection{Differencing method}

If the series has an element such as trend or seasonality, then by taking the regular or seasonal differences those elements can be eliminated from the series and it is defined as $W_{t}=Y_{t}-Y_{t-L}$, where $Y_{t}$ is the response variable at time $t$ and $L$ is the length of the season.

\section{Autocorrelation function and partial auto correlation function}

In time series analysis, a process of examining the autocorrelation function (ACF) and partial autocorrelation function (PACF) is to determine the nature of the process under consideration. 


\subsubsection{Autocorrelation function}

Autocorrelation function ( $\mathrm{ACF}$ ) at lag $\mathrm{k}$ is defined by

$$
\rho_{k}=\frac{\operatorname{cov}\left[\left(Y_{t}-\hat{Y}_{t}\right)\left(Y_{t+k}-\hat{Y}_{t+k}\right)\right]}{\sqrt{\operatorname{var}\left(Y_{t}-\hat{Y}_{t}\right) \operatorname{var}\left(Y_{t+k}-\hat{Y}_{t+k}\right)}}
$$

The first several autocorrelations are persistently large in the graph of ACF and trailed off to zero rather slowly, it can be assumed that a trend exists and the time series is non-stationary. If the series is stationary, then ACF graph must decay exponentially.

\subsubsection{Partial autocorrelation function}

Partial autocorrelation function (PACF) between $Y_{t}$ and $Y_{t+k}$ is the conditional correlation between $Y_{t}$ and $Y_{t+k}$ and defined as follows: $\phi_{k k}=\operatorname{corr}\left(Y_{t}, Y_{t+k} \mid Y_{t+1}, Y_{t+2}, \ldots, Y_{t+k-1}\right)$

In other words, the PACF between $Y_{t}$ and $Y_{t+k}$ is the autocorrelation between $Y_{t}$ and $Y_{t+k}$ after adjusting for $Y_{t-1}, Y_{t-2}, \ldots, Y_{t-k+1}$.

\subsection{Dynamic Transfer Function modelling method}

Dynamic transfer function (DTF) model is a statistical model describing the relationship between an output variable $Y_{t}$ and one or more input variables $X_{t}$ 's. It has many applications especially in forecasting turning points.

\subsubsection{Dynamic Transfer Function - Noise model}

In practice, the output $Y_{t}$ is not a deterministic function of $X_{t}$. It is often disturbed by some noise or has its own dynamic structure. The noise component $N_{t}$ may be serially correlated, and it is assumed that $N_{t}$ follows an $\operatorname{ARMA}(p, q)$ model as $\phi(B) N_{t}=\theta(B) e_{t} \quad$ where $\phi(B)=1-\phi_{1} B-\phi_{2} B^{2}-\ldots-\phi_{p} B^{p} \quad$ and $\theta(B)=1-\theta_{1} B-\theta_{2} B^{2}-\ldots-\theta_{q} B^{q} \quad$ are polynomials in $B$ of degree $p$ and $q$ respectively, and $\left\{e_{t}\right\}$ is a sequence of independent and identically distributed random variables with mean zero and variance $\sigma_{e}^{2}$.

It is noted that in the above ARMA model, $E\left(N_{t}\right)=0$ and the usual conditions of stationarity and invertibility apply. Putting together, a simple DTF model can be obtained as $Y_{t}=c+v(B) X_{t}+N_{t}=c+\frac{\omega(B) B^{b}}{\delta(B)} X_{t}+\frac{\theta(B)}{\phi(B)} e_{t}$ where $c$ is a constant, $\theta(B), \phi(B), \omega(B)$ and $\delta(B) \quad$ are defined similarly as before with degree $q, p, s$, and $r$ respectively, and $\left\{e_{t}\right\}$ are white noise series. The parameter $b$ is called the decay rate of the system. The noise component $N_{t}$ should be independent of $X_{t}$; otherwise, the model is not identifiable.

Further it is noted that when $b>0$ the DTF model is useful in predicting the turning points of $Y_{t}$ given those of $X_{t}$.

\subsubsection{Dynamic Transfer Function model for Univariate Time Series Process}

A general form of a DTF model can be expressed as

$$
Y_{t}=c+\sum_{i=1}^{m} \frac{\omega_{i}(B) B^{b i}}{\delta_{i}(B)} X_{i t}+\frac{\theta(B)}{\phi(B)} e_{t}
$$


where $\omega_{i}(B)=\omega_{0}+\omega_{1} B+\omega_{2} B^{2}+\ldots+\omega_{i} B^{i}$

$$
\delta_{i}(B)=\delta_{0}+\delta_{1} B+\delta_{2} B^{2}+\ldots+\delta_{i} B^{i}
$$

$\phi(B)=1-\phi_{1} B-\phi_{2} B^{2}-\ldots-\phi_{p} B^{p}$

and

$\theta(B)=1-\theta_{1} B-\theta_{2} B^{2}-\ldots-\theta_{q} B^{q}$

are

polynomials in $B$ of degree $q, p, s$, and $r$ respectively, and $\left\{e_{t}\right\}$ are white noise series. The parameter $b i$ is called the decay rate with the $\mathrm{i}^{\text {th }}$ variable. The order of the DTF is said to be $(r, s, b)$ and the added noise model is of order $(p, q)$.

Since the DTF model is a straight forward extension of the ARMA model, for $\omega_{i}(B)=0$, the model is equivalent to univariate time series process (Dominique et al., 2002). Thus the DTF for univariate time series can be simply written as $Y_{t}=\frac{\theta(B)}{\phi(B)} e_{t}$.

\subsection{Residual Analysis}

Before using the model for forecasting, it must be checked for adequacy. Diagnostic checks are performed to determine the adequacy of the model. Accordingly, the residuals should be random and normally distributed with constant variance. The following tests are carried out for the residual analysis:

\subsubsection{Anderson- Darling}

The Anderson- Darling (AD) test is used to test if a sample of data comes from a population with a specific distribution. It is a modification of Kolmogorov-Smirnov (K-S) test and gives more weight to the tails than does the K-S test. Here the hypotheses are $\mathrm{H}_{0}$ : The data follow normal distribution versus $\mathrm{H}_{1}$ : The data do not follow normal distribution.

The test statistic of $\mathrm{AD}$ test is:
$A^{2}=-N-\sum_{i=1}^{N} \frac{(2 i-1)}{N}\left[\ln F\left(Y_{i}\right)+\ln \left(1-F\left(Y_{N+1-i}\right)\right)\right]$

where $F$ is the cumulative distribution function of the specified distribution, $Y_{i}$ are the ordered data and $N$ is the total number of observations.

\subsubsection{Lagrange's Multiplier test}

Lagrange's Multiplier (LM) test is used to test the independency of residuals. It is an alternative test of Durbin Watson test for auto correlation among residuals. The null hypothesis to be tested is that, $\mathrm{H}_{0}$ : there is no serial correlation of any order. The individual residual autocorrelations should be small. Significant residual autocorrelations at low lags or seasonal lags suggest that the model is inadequate. The test statistic of LM test is:

$W=n R^{2} \square \chi_{d f}^{2} \quad$ where, $d f$ is the number of regressors in the auxiliary regression (only linear terms of the dependent variable are in the auxiliary regression), $R^{2}$ is the determination of coefficients and $n$ is the number of observations.

\subsubsection{White's General test}

White's general test is used in order to check constant variance of residuals. Accordingly the null hypothesis is $\mathrm{H}_{0}$ : Homoscedasticity against the alternative hypothesis $\mathrm{H}_{1}$ : Heteroscedasticity. Test statistic of White's General test is:

$W=n R^{2} \square \chi_{d f}^{2} \quad$ where, $d f$ is the number of regressors in the auxiliary regression (squared terms of the dependent variable are also included in addition to terms in the LM test in auxiliary regression), $R^{2}$ is the determination of coefficients and $n$ is the number of observations.

\section{Model Validation}

It is important to evaluate performance of fitted model on the basis of the fit of the forecasting. 
Measure of forecast accuracy should always be evaluated as part of a model validation effort.

\section{4. Mean absolute percentage error}

Mean absolute percentage error (MAPE) is the average of the sum of the absolute values of the percentage errors. It is generally used for evaluation of the forecast against the validation sample. To compare the average forecast accuracy of different models, MAPE statistics is used. It is defined as, MAPE $=\frac{1}{n} \sum_{t=1}^{n}\left|\frac{Y_{t}-\hat{Y}_{t}}{Y_{t}}\right| \times 100$, where $Y_{t}$ is the response variable at time $t$ and $n$ is the number of observations. Practically if MAPE is less than $10 \%$ then the fitted model is highly recommended for forecasting.

\section{RESULTS \& DISCUSSIONS}

In this section, the discussions are based on the results obtained from the results software MINITAB and SAS.

\subsection{Preliminary Analysis}

The Figure 1 shows the yearly international tourist arrivals from the year 1967 to 2015 to Sri Lanka.

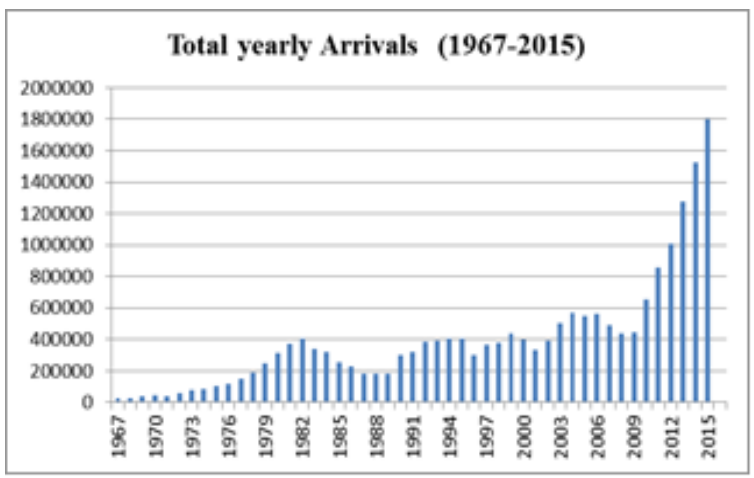

Figure 1. Plot of yearly tourist arrivals

In Figure 1, it is clearly observed that, from the years 1967 to 1982 there is an upward trend in arrivals. This is the beginning of the internal conflict in Sri Lanka. There after ups and downs in total arrivals can be seen from the years 1983 to 2009. This is the period where the internal conflict took place in Sri Lanka. Nevertheless, from the years 2009 to 2015, after the internal conflict, there is a remarkable upward trend in the total number of international tourist yearly arrivals to the island. This is the reason for this study is to mainly focus on the international tourist arrivals, only after the conflict, to Sri Lanka.

To study the behaviour of the arrivals, after the internal conflict, data from June 2009 to December 2015 are considered whereas only for growth rate calculation the data from January 2008 are taken. The relevant results are summarized in Table 1. It is noted that, the original data is named as $\mathrm{Y}$ in the analysis part to handle this in SAS and MINITAB software conveniently.

Table 1. Annual tourist arrivals and its growth rate

\begin{tabular}{|l|l|l|l|l|l|}
\hline Year & Arrivals & $\begin{array}{l}\text { Rrowth } \\
\text { Rate }\end{array}$ & Year & Arrivals & $\begin{array}{l}\text { Growth } \\
\text { Rate }\end{array}$ \\
\hline $\mathbf{2 0 0 9}$ & 260161 & $2.15 \%$ & $\mathbf{2 0 1 3}$ & 1274593 & $26.75 \%$ \\
\hline $\mathbf{2 0 1 0}$ & 654476 & $46.12 \%$ & $\mathbf{2 0 1 4}$ & 1527153 & $19.81 \%$ \\
\hline $\mathbf{2 0 1 1}$ & 855975 & $30.79 \%$ & $\mathbf{2 0 1 5}$ & 1798380 & $17.76 \%$ \\
\hline $\mathbf{2 0 1 2}$ & 1005605 & $17.48 \%$ & \multicolumn{2}{|c|}{ Total arrivals } & $\mathbf{7 , 3 7 6 , 3 4 3}$ \\
\hline
\end{tabular}

From the statistics appeared in Table 1, it can be stated that, over 7.3 million tourists had visited the island during the study period. Also only in the year 2015 nearly 1.8 million tourists had visited the island and which is the biggest hit in tourism history of Sri Lanka.

Further it is noted that, every year there is a positive growth rate. It reveals that, there is dramatic increase in total tourist arrivals after the conflict. A rapid increase in growth rate in the year 2010, soon after the internal conflict in Sri Lanka, is also noted here. 
The monthly average arrivals after the conflict are also taken into account to see the pattern of the arrivals to Sri Lanka.

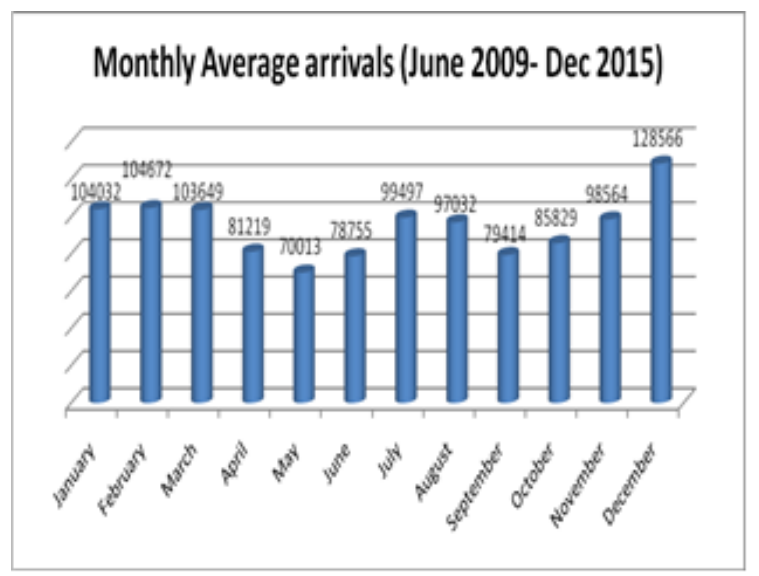

Figure 2. Plot of monthly average arrivals

It can be clearly observed a pattern of arrivals, on the average, from Figure 2 that in the months of December, January and February more tourists do come to Sri Lanka whilst the lower numbers of arrivals are recorded in the months of May and June on average in every year.

\subsection{Checking stationary condition}

Figure 3 provides the time series plot of the original series Y from June 2009 to December 2015.

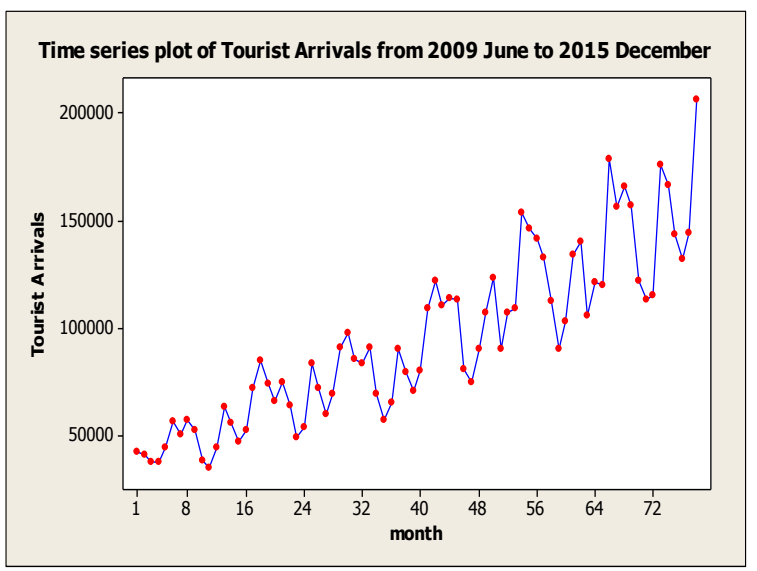

Figure 3. Plot of Time series

An upward trend with seasonal pattern can be clearly seen from the time series plot of the original series in Figure 3. Hence, it is obvious that, the original series $\mathrm{Y}$ is non- stationary.

Further, to check the stationary condition of the series Y, statistically, ACF graph with ADF and Kruskal- Wallis tests are employed as follows:

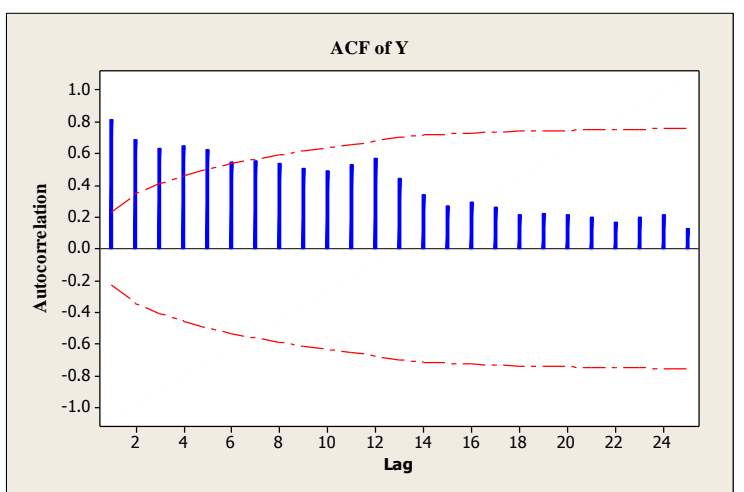

Figure 4. ACF graph of the series $\mathrm{Y}$

It is very clear from the graph of ACF of $\mathrm{Y}$ in Figure 4 that it does not decay exponentially and thus it can be claimed that the original series $\mathrm{Y}$ is non- stationary.

Since the p- value (0.99) of ADF test confirms the existence of the trend in the series $\mathrm{Y}$, the regular difference is taken to remove the trend and now the first differenced series is named as D1Y. Again the time series plot of the series D1Y is obtained to observe the behaviour of the regular differenced series.

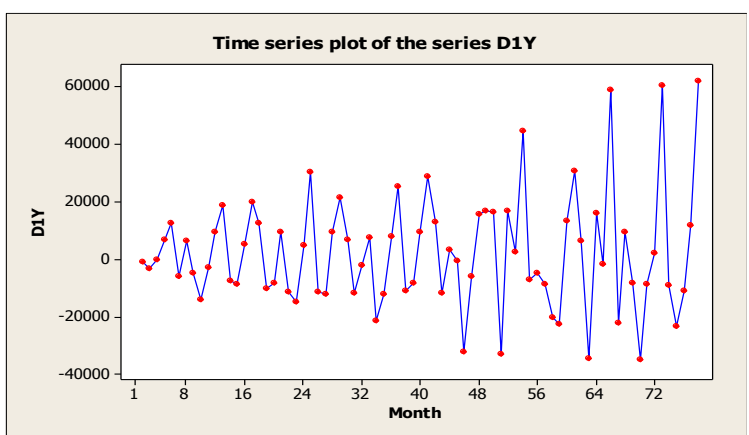

Figure 5. Time series plot of D1Y

Now it seems from the time series plot in Figure 5 that there is no trend in the series D1Y. Again $\mathrm{ADF}$ test for the series D1Y is also applied and hence it concludes that the series D1Y has no 
trend as the p-value of ADF test for D1Y is 0.00 . However, the p- value (0.00) of Kruskal- Wallis test for the series D1Y still confirms the existence of seasonality.

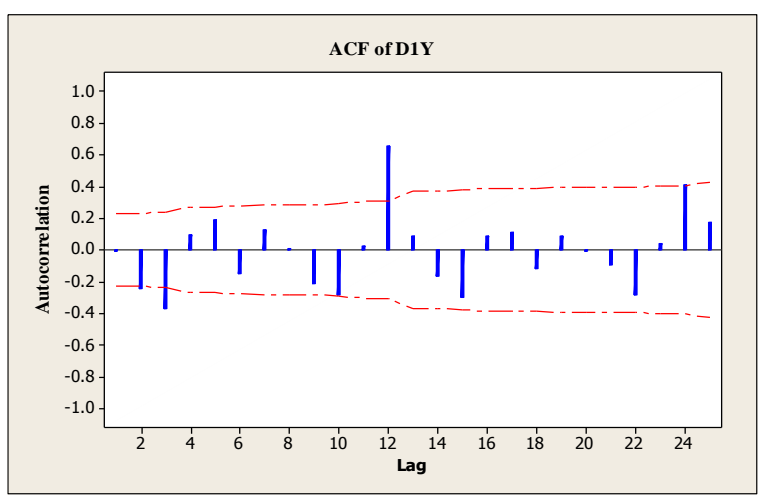

Figure 6. ACF graph of the series D1Y

From the graph of ACF of D1Y in Figure 6, it can be clearly observed that, spikes of 12th and 24th lags are high and not significant. Therefore, it can be assumed that the series D1Y has the seasonality with length 12 . To remove this seasonality, the seasonal difference for length 12 is taken and now it is named as D12D1Y.

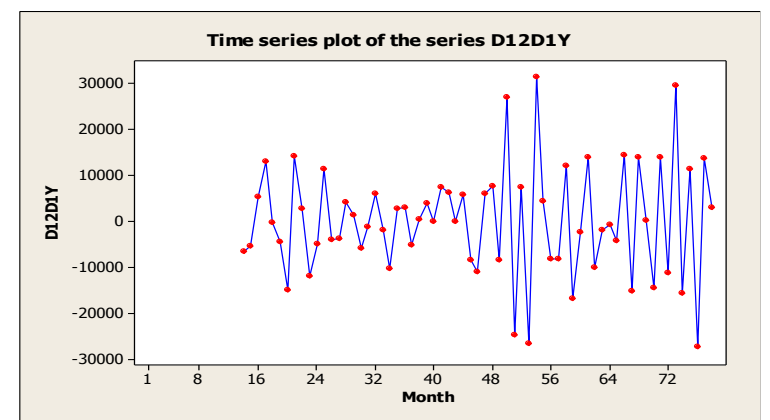

Figure 7. Time series plot of D12D1Y

Time series plot of the series D12D1Y is obtained to observe the behaviour of the 12th differenced series. Time series plot in Figure 7 also suggests that the seasonal differenced series, D12D1Y, with length 12 has no trend. However, it is hard to come to a conclusion about the seasonality. Thus the relevant statistical tests, ADF and Kruskal- Wallis, with ACF and PACF graphs are to be used to make a conclusion on stationary condition of the series D12D1Y.

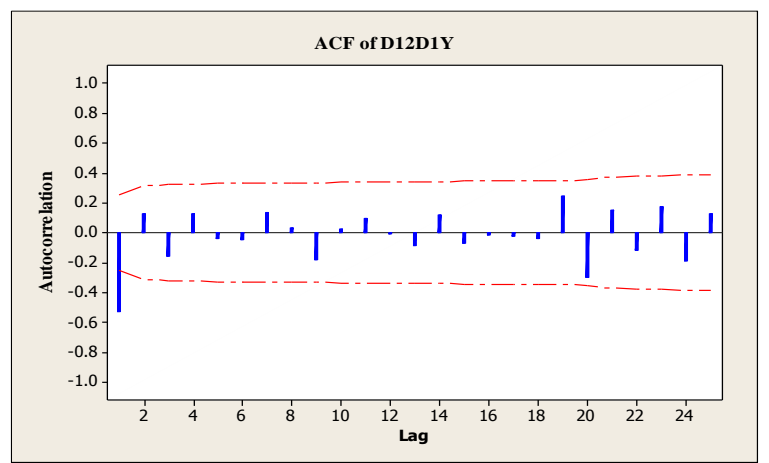

Figure 8. ACF graph of the series D12D1Y

Except at the first lag all the spikes are small and they are significant in the graph of ACF of the series D12D1Y in Figure 8. In addition, all the spikes after first lag are small and significant in the graph of PACF of the series D12D1Y. Both graphs indicate that, the new series D12D1Y is stationary.

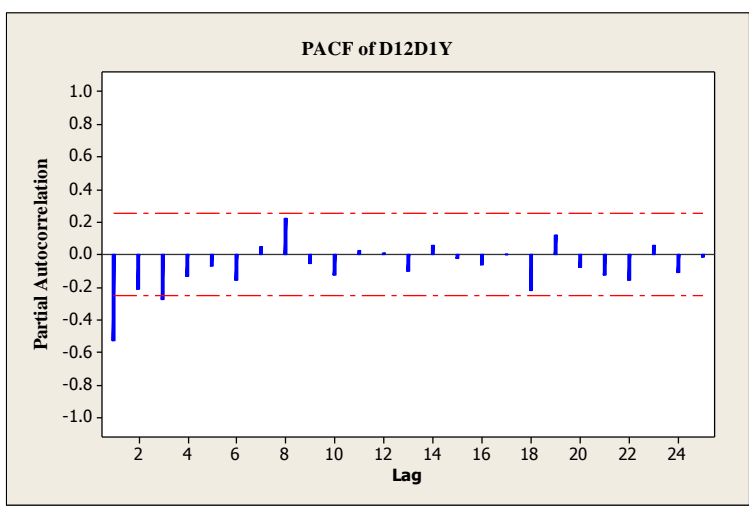

Figure 9. PACF graph of the series D12D1Y

Moreover, the p-value (0.00) of ADF test for D12D1Y shows that, it has no unit root. Therefore it can be concluded with $95 \%$ confidence that, D12D1Y has no trend. At the same time, from the p-value (0.37) of KruskalWallis test, it can be concluded that the D12D1Y is now free from the seasonal pattern. Therefore, the new series D12D1 Yis stationary and it can be used to fit the dynamic transfer function model.

\subsection{Fitting dynamic transfer function model}

The stationary data D12D1Y feed to SAS program to fit DTF model for univariate time series process. According to its output, the 
estimated parameter is and p- value of the parameter estimation is less than 0.0001 . Therefore it can be concluded with $95 \%$ confidence that, the parameter of the model is significant.

Hence, the fitted DTF model to predict international tourist arrivals to Sri Lanka is:

$\hat{Y}_{t}=Y_{t-1}+Y_{t-12}-Y_{t-13}+0.82 * e_{t-1}$

where $\hat{Y}_{t}$ is the estimated tourist arrivals at time $t$

$Y_{t-1}, Y_{t-12}$ and $Y_{t-13}$ are the preceding arrivals at time $t-1, t-12$ and $t-13$ respectively

$e_{t-1}$ is the residuals at one preceding period $t-1$

\subsection{Residual analysis of the fitted DTF model}

The residual analysis to the fitted model to check for the adequacy is carried out as follows:

\subsubsection{Normality checking}

The probability plot of residuals of fitted DTF model is almost linear in Figure 10 and further the p-value (0.820) of the Anderson Darling test suggests that the residuals follow normal distribution. Thus it can be concluded with $95 \%$ confidence that the residuals are normally distributed.

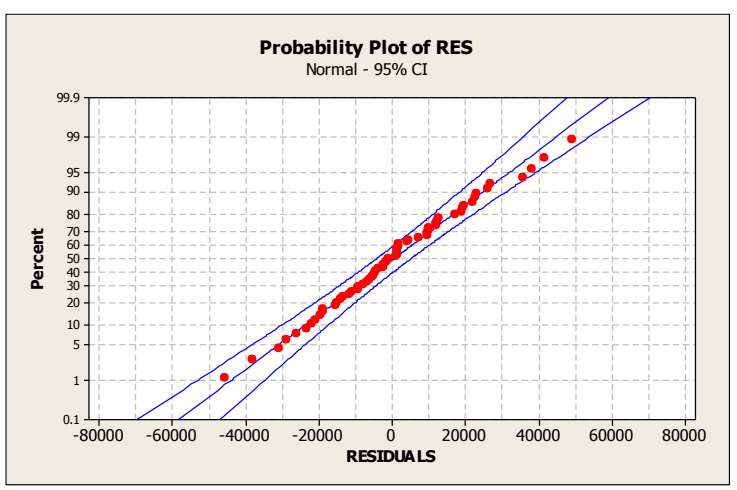

Figure 10. Normal probability plot of residuals

\subsubsection{Independency checking}

From the plot of residuals versus predicted values in Figure 11, it can be seen that the residuals scatted randomly. Thus it can be stated that the residuals are independently distributed. Further, the p- value (0.62) of Lagrange's Multiplier test confirms that, the residuals of fitted DTF model have no auto correlation.

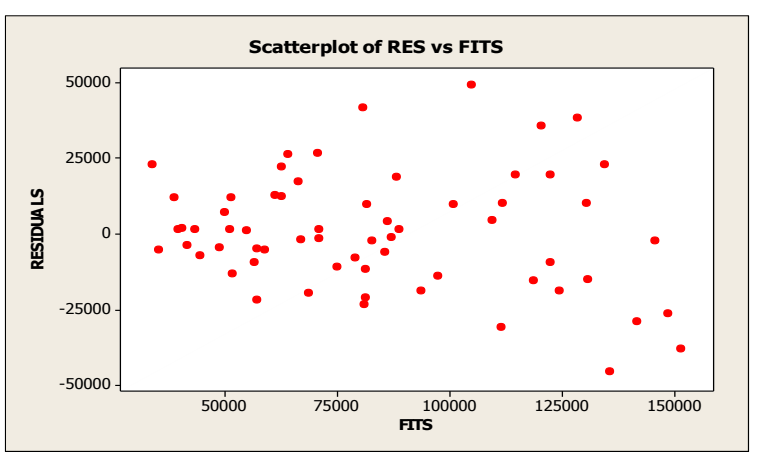

Figure 11. Plot of residuals versus predicted values

\subsubsection{Homoscedasticity checking}

In addition, the plot of residuals versus observations order in Figure 12 shows that it does not follow any systematic pattern and it is symmetric about 0 . Thus it can be claimed that the variance of the residuals is constant throughout. Moreover, the p-value (0.30) of White's general test confirms with $95 \%$ confidence that the residuals of fitted DTF model have no heteroscedasticity.

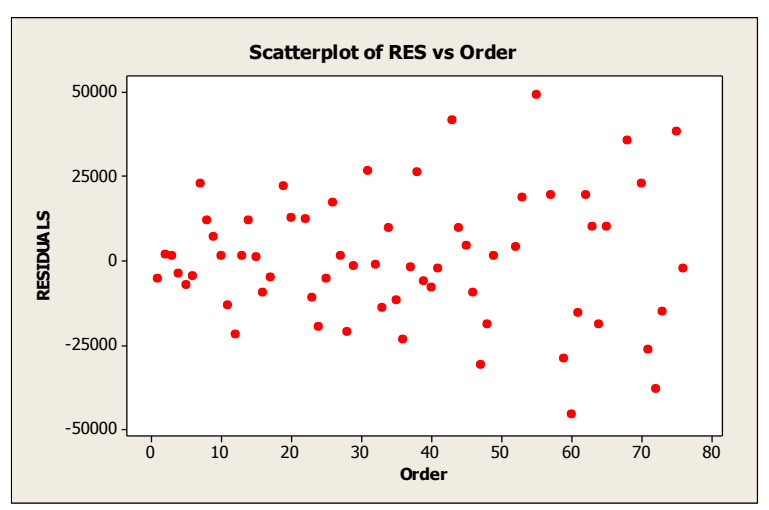

Figure 12. Plot of residuals versus observations order 
The residuals of the fitted DTF model satisfy all necessary conditions of the residual analysis. Therefore, it can be concluded that the fitted DTF model is significant. Hence, this model can be recommended for predicting future international tourist arrivals to Sri Lanka.

\subsection{Model validation}

The plot in Figure 13 clearly shows that the predicted value from the first six months in 2016 period is very closer to the actual observations that of in the same periods in 2016. It is noted that, in the first three months the predicted values under estimate and however in the last there months they over estimate. Geometric representation of model validation in Figure 13 indicates that the predicted values are closer to the observed values. However, it has to be justified by using statistical method.

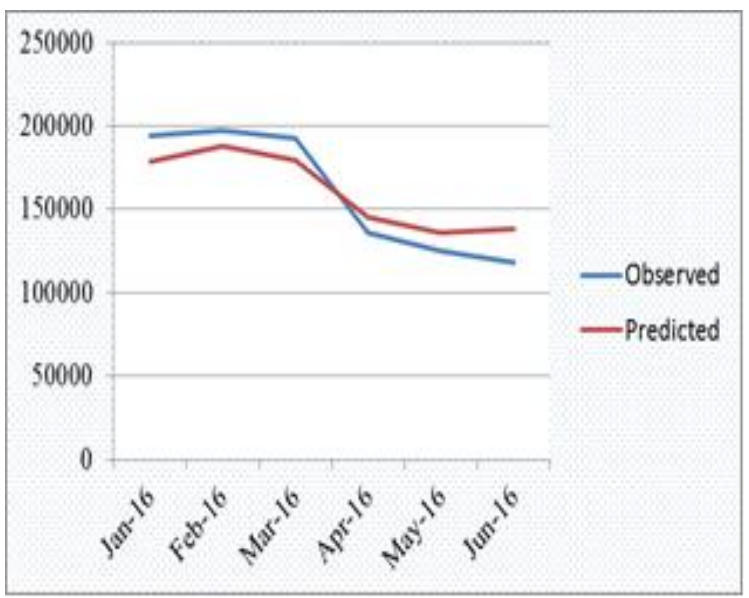

Figure 13. Plot of observed and predicted values

To check the accuracy of fitted model as model validation, MAPE statistic is calculated from the period from January 2016 to June 2016. The predicted arrivals with the observed arrivals in that particular period are summarized in Table 2.

According to the MAPE value (8.63) in Table 2, it can be concluded that, the fitted DTF model explains over $90 \%$ accuracy in terms of forecasting. This model can be strongly recommended to forecast future tourist arrival to Sri Lanka.
Table 2. Observed and predicted arrivals in 2016

\begin{tabular}{|l|l|l|}
\hline Month in 2016 & Observed & Predicted \\
\hline January & 194280 & 179003 \\
\hline February & 197697 & 188298 \\
\hline March & 192841 & 179808 \\
\hline April & 136367 & 144974 \\
\hline May & 125044 & 136286 \\
\hline June & 118038 & 138224 \\
\hline MAPE & \multicolumn{2}{|c|}{$\mathbf{8 . 6 3}$} \\
\hline
\end{tabular}

\subsection{Forecasting future arrivals in $\mathbf{2 0 1 6}$}

The future arrivals for last six months in the year 2016 are forecasted and reported in Table 3.

Table 3. Forecasted arrivals in 2016

\begin{tabular}{|l|l|}
\hline Month in 2016 & Predicted Arrivals \\
\hline July & 198,561 \\
\hline August & 189,367 \\
\hline September & 166,131 \\
\hline October & 155,037 \\
\hline November & 166,904 \\
\hline December & 228,871 \\
\hline Total Arrivals & $\mathbf{1 , 1 0 4 , 8 7 1}$ \\
\hline
\end{tabular}

Based on the monthly wise forecasted arrivals from July 2016 to December 2016 in Table 3, it can be expected that over 1.105 million tourists will come to Sri Lanka in the last six months in 2016. It is approximately $14 \%$ increase in the tourist arrivals over the last six months in the year 2015 .

\section{CONCLUSIONS}

Based on this study, here we provide some recommendations which can be made to improve the tourism industry in Sri Lanka.

\subsection{Pattern of tourist arrivals to Sri Lanka}

Since the tourist arrivals have been dramatically increased in recent past, particularly after the internal conflict in Sri Lanka, it is recommended for more attention on this industry is needed in 
the country. Since the seasonal patterns are very clearly observed, it is recommended to promote some activities to attract the tourists especially in off periods.

\subsection{Fitted DTF model}

The fitted DTF model to predict the international tourist arrivals to Sri Lanka is $\hat{Y}_{t}=Y_{t-1}+Y_{t-12}-Y_{t-13}+0.82 * e_{t-1}$

where $\hat{Y}_{t}$ is the estimated tourist arrivals at time $t$

$Y_{t-1}, Y_{t-12}$ and $Y_{t-13}$ are the preceding arrivals at time $t-1, t-12$ and $t-13$ respectively $e_{t-1}$ is the residuals at one preceding period $t-1$

\subsection{Prediction of future arrivals}

Over 1.1 million international tourists can be expected in the last six months of the year 2016 and it will be $14 \%$ increase with the year 2015 . Therefore it is better to be ready to facilitate the needs of those visitors in future.

\subsection{Further Work}

Since tourism contributes to national revenue of Sri Lanka in a large scale, it is better to carry out a causal relation study of international tourist arrivals to Sri Lanka versus gross domestic product (GDP) and then it would be useful to fit a dynamic transfer function (DTF) model by considering GDP as the dependent variable and tourist arrivals as the independent variable.

\section{REFERENCES}

ATHANASOPOULOS G \& HYNDMAN RJ. Modelling and forecasting Australian domestic tourism. Preprint submitted to Tourism Management. 2006. Available in http://www.robjhyndman.com/papers/austouris m.pdf. Accessed on $29^{\text {th }}$ Nov 2016.
BALAGUER J \& CANTAVELLA JM. Tourism as a long-run economic growth factor: the Spanish case. Applied Economics. 2002; 34: 877-884.

BERMUDEZ JD, SEGURA JV \& VERCHER E. Holt- Winters forecasting: an alternative formulation applied to UK air passenger data. Journal of Applied Statistics. 2007; 34: 10751090.

BURGER CJSC, DOHNAL M, KATHRADA M \& LAW R. A practitioners guide to time-series methods for tourism demand forecasting - a case study of Durban, South Africa. Tourism Management. 2001; 22: 403-409.

CHANG JL, HSUEH FC \& TIAN SL. Forecasting tourism demand using time series, artificial neural networks and multivariate adaptive regression splines: Evidence from Taiwan. International Journal of Business Administration. 2011; 2(2): 14-24.

CHO V. Tourism forecasting and its relationship with leading economic indicators. Journal of Hospitality and Tourism Research. 2001; 24: 399-420.

CHO V. A comparison of three different approaches to tourist arrival forecasting. Tourism Management. 2003; 24: 323-330.

CHU F. Forecasting tourism demand in AsianPacific countries. Annals of Tourism Research. 1998; 25(3): 597- 615.

DIMITRIOS G, DIMITRIS P \& DANIEL S. Forecasting tourist arrivals in Greece and the impact of macroeconomic shocks from the countries of tourists' origin. Annals of Tourism Research. 2012; 39 (2): 641-666.

DOMINIQUE MH, LEONARD JP \& RANDALL LS. Market response modelsEconometric and Time Series Analysis (2nd Edition). Jehoshua E, editor. International Series in Quantitative Marketing. Kluwer academic. $2002 ; 286$. 
DURBARRY R. Tourism and economic growth: the case of Mauritius. Tourism Economics. 2004; 10: 389-401.

GNANAPRAGASAM SR \& COORAY TMJA. An empirical analysis of forecasting international tourist arrivals to Sri Lanka by using Box-Jenkin's method: A postwar perspective. Proceedings of Wayamba International Conference (WinC2016) 2016(a); 19.

GNANAPRAGASAM SR \& COORAY TMJA. Tourist arrivals after the internal conflict in Sri Lanka: A time series analysis using HoltWinter's method. Proceedings of Open University Research Sessions (OURS 2016). 2016(b); 59.

GNANAPRAGASAM SR, COORAY TMJA \& DISSANAYAKE R. Prediction of international tourist arrivals to Sri Lanka using state space modeling method: An empirical study after the civil war, Proceedings of 9th International Research Conference on Professional Integration for a Secure Nation (IRC2016). 2016; 202.

KING BEM \& GAMAGE A. Maximizing the value of the ethnic connection: Expatriate travelers from Australia to Sri Lanka. Journal of Travel Research. 1994; 33: 46-52.

KURUKULASOORIYA N \& LELWALA E. Time series behavior of burgeoning international tourist arrivals in Sri Lanka: The post- war experience. Ruhuna Journal of Management and Finance. 2014; 1(1): 1-14.

LAW R. Back-propagation learning in improving the accuracy of neural network based tourism demand forecasting. Tourism Management. 2000; 21: 331-340.

LIM C \& MCALEER M. Forecasting tourism arrivals. Annals of Tourism Research. 2001; 28: 965-977.

LOGANATHAN N \& YAHAYA I. Forecasting international tourism demand in Malaysia using
Box Jenkins SARIMA application. South Asian Journal of Tourism and Heritage. 2010; 3(2): 5060.

PRASERT C, CHUKIAT C \& RATCHANEE M. Time series models for forecasting international visitor arrivals to Thailand. International Conference on Applied Economics - ICOAE. 2008; 159-163.

SAAYMAN A \& SAAYMAN M. Forecasting tourist arrivals in South Africa. Acta Commercii. 2010; 281-293.

SONG H \& LIB G. Tourism demand modelling and forecasting-A review of recent research. Tourism Management. 2008; 23: 203-220.

WICKREMASINGHE GB \& IHALANAYAKE $\mathrm{R}$. The causal relationship between tourism and economic growth in Sri Lanka: Some empirical evidence, working paper series, School of Applied Economics. 2006. Available in https://www.researchgate.net/publication/22858 2285_The_Causal_Relationship_between_Touri Touri_Economic_Growth_in_Sri_Lanka_SomS _Empirical_Evidence. Accessed 29th Nov 2016.

WITT SF, NEWBOULD GD \& WATKINS AJ. Forecasting domestic tourism demand: application to Las Vegas arrivals data. Journal of Travel Research. 1992; 31: 36-41. 